This PDF is a selection from a published volume from the National Bureau of Economic Research

Volume Title: Commodity Prices and Markets, East Asia Seminar on Economics, Volume 20

Volume Author/Editor: Takatoshi Ito and Andrew K. Rose, editors

Volume Publisher: University of Chicago Press

Volume ISBN: 0-226-38689-9

ISBN13: 978-0-226-38689-8

Volume URL: http://www.nber.org/books/ito_09-1

Conference Date: June 26-27, 2009

Publication Date: February 2011

Chapter Title: Oil Shocks in a DSGE Model for the Korean Economy

Chapter Authors: Sungbae An, Heedon Kang

Chapter URL: http://www.nber.org/chapters/c11883

Chapter pages in book: (295 - 321) 


\title{
Oil Shocks in a DSGE Model for the Korean Economy
}

\author{
Sungbae An and Heedon Kang
}

\subsection{Introduction}

The Western Texas Intermediate (WTI) crude oil price was 29.19 U.S. dollars per barrel at the third quarter of 2003 and it peaked at 139.96 dollars by the third quarter of 2008. This rapid and continual rise in oil prices over recent years posed many questions among the general public as well as economists. Since the Korean economy depends entirely on imports for its acquisition of crude oil, households, entrepreneurs, and policymakers are interested in knowing to what extent the rise in oil prices affects the economy.

There are various channels through which changes of oil prices have effects on the economy. In our model economy, an oil price shock is reflected through the oil consumption. It generates income and substitution effect because oil is included in the consumption bundle of a typical household; that is, oil is directly consumed. An oil price shock also affects a firm's decision, which results in substitution of oil input in production with capital and labor hiring. The marginal costs of production faced by firms and their pricing decisions are affected; this generates dynamic effects when prices are rigid. Also the substitution with capital in production affects decisions on the capital accumulation, and this brings along long-run effects. We do not

Sungbae An is assistant professor in the School of Economics at Singapore Management University. Heedon Kang is an economist in the Research Department of the Bank of Korea.

We thank Mario Crucini, Takatoshi Ito, Warwick McKibbin, Andrew Rose, Etsuro Shioji, Pengfei Wang, and conference participants at the 20th NBER-EASE conference in Hong Kong for helpful comments. The views expressed in this article are those of authors and do not necessarily reflect those of the Bank of Korea. Any errors or omissions are the responsibility of the authors. 
Table 9.1

Oil uses: Korea (2005) (volume, percent)

\begin{tabular}{lcccccr}
\hline & Industry & Transport & $\begin{array}{c}\text { Home and } \\
\text { commercial }\end{array}$ & Public & Other & Total \\
\hline Gasoline & 0.27 & 7.48 & 0.01 & 0.07 & & 7.83 \\
Kerosene & 0.72 & 0.01 & 4.27 & 0.09 & 0.09 & 5.18 \\
Diesel & 2.52 & 14.64 & 1.08 & 0.47 & 0.02 & 18.73 \\
Bunker & 5.56 & 3.05 & 1.08 & 0.04 & 3.49 & 13.21 \\
Naphtha & 35.90 & & & & & 35.90 \\
Solvent & 0.58 & & & & & 0.58 \\
Jet Oil & & 2.67 & & 0.62 & & 3.29 \\
LPG & 2.70 & 5.70 & 3.43 & 0.03 & 0.18 & 12.04 \\
Asphalt & 1.38 & & & & & 1.38 \\
Lubricant & 0.65 & & & & & 0.65 \\
Etc. & 0.81 & & 0.41 & & & 1.22 \\
Total & 51.09 & 33.55 & 10.27 & 1.30 & 3.78 & 100.00 \\
\hline
\end{tabular}

explicitly model the speculative motive of oil consumption and trading that can change the expectation formation and we assume that international oil prices are purely exogenous.

The composition of oil use in Korea is reported in table 9.1. By sector, the fuel for transportation accounts for 34 percent of oil consumption in 2005 while industrial use occupies 51 percent. Home and commercial share is 10 percent. Along the rows shares are listed by types of oil from a petroleum refinery. At a first glance we can notice that use of a certain type of oil is tightly linked to a certain sector. For example, most of gasoline and diesel are used as the fuel for transportation and kerosene is mostly used as the fuel for heating in home and commercial sector. Naphtha, solvent, asphalt, and lubricant are exclusively used in industry. Particularly we note that the naphtha occupies 36 percent of total oil use and that it is the main input for the petrochemical industry that produces plastic-related products. Because of this clear separation of oil use by type, the imported crude oil after the refinery can be categorized into direct consumption (fuels for transportation and heating) and input of production.

We present the model economy that uses oil imports either as direct consumption or an input of production. The model is a conventional New Keynesian model for a small open economy with an augmentation of oil uses. Within Bayesian estimation framework including dynamic stochastic general equilibrium-vector autoregressions (DSGE-VARs), the empirical analysis is performed based on the Korean aggregate data. The DSGEVAR procedure developed by Del Negro and Schorfheide (2004) provides an assessment tool of DSGE model specifications. By Bayesian analysis, we first perform model comparison to check the importance of each channel that transmits an oil price shock to the economy. The model comparison is extended to VAR models whose coefficients are restricted by DSGE models 
a priori with various degrees of tightness. In terms of fitting the data, an optimal degree of tightness; that is, an "optimal" combination between the VAR and a DSGE model is found. We can also derive more sensible impulse responses from VARs that are in line with those from the DSGE models.

We find that the model economy produces reasonable posterior estimates of the structural parameters and works relatively well compared to impulse responses from the VAR with optimal prior weight from the DSGE model. The misspecification becomes very severe when either consumption or production motive of oil imports is ignored. From the variance decomposition analysis, we conclude that the variability of the domestic interest rate can be explained mainly by the oil price shocks transmitted to domestic oil prices. The shock to the deviation from the law of one price (LOP) in oil prices has an important role in explaining variability of most observables. The impulse response analysis shows that the oil price shock has negative impacts on most of the observables at first, but it brings in positive and hump-shaped responses in a medium run. This prolonged response is mainly due to the interplay of the substitution and income effect. The low substitution elasticities between oil and core consumption, and between oil-capital aggregate and labor input, prevent the quick adjustment. In a medium run where the rigid prices and wages are renewed, the income effect from increased demand for Home goods plays an important role. We also calculate the pass-through of oil prices into the core consumption price index using estimated DSGE and VAR models and find that the passthrough is relatively low in both cases. Finally, the deviation from the LOP in oil prices has decreased but the government accommodating tax policy played a limited role during this period. Therefore, a more elaborated model on government behavior is anticipated to investigate the pass-through of oil price shocks.

The rest of the chapter is organized as follows. Section 9.2 sets up a small open economy model with oil. Section 9.3 describes data and estimation methods including DSGE-VARs, the main tool for empirical analysis used in this chapter. Section 9.4 discusses empirical findings, and section 9.5 concludes.

\subsection{The Model}

Following Bouakez, Rebei, and Vencatachellum (2008) and Medina and Soto (2005), we model an economy where imported oil is either directly consumed by households or used as an input of production. Most common source of direct consumption is fuel for heating and transportation. It is also obvious that oil is used in the production. Noting that the oil use and the capital are substitutable in production, we introduce the capital unlike Medina and Soto (2005).

Households are heterogeneous in the sense that they are monopolistic 
labor suppliers but wage setting by each household is limited by reoptimization probability. Each household's consumption basket consists of Home and Foreign goods and oil. Firms are monopolistically competitive firms that produce differentiated goods. Just like the wage setting of households, the price-setting behavior is characterized á la Calvo (1983), which introduces nominal stickiness of output price of the economy. The government plays a passive role in this model, where it runs a balanced budget without any government spending. Monetary authority plays monetary policy based on the interest rate feedback rule. As an open economy, imports consist of oil and Foreign goods either for consumption and investment while only Home goods that are produced with oil, capital, and labor are exported. Exchange rate pass-through is perfect for import and export prices, with the exception of oil prices. Since we treat the Korean economy as a small open economy, foreign sectors are modeled as a set of exogenous processes.

\subsubsection{Households}

The domestic economy is populated by a continuum of monopolistically competitive households indexed by $j \in[0,1]$. Each household supplies a differentiated labor services to firms. There exists a set of perfectly competitive employment agencies that combine the different labor services from households into an aggregate labor index $H_{t}$, defined as

$$
H_{t}=\left(\int_{0}^{1} H_{t}(j)^{v_{L} /\left(v_{L}-1\right)}\right)^{v_{L} /\left(v_{L}-1\right)},
$$

where $v_{L}$ is the elasticity of substitution across different labor services. Let $W_{t}(j)$ denote the nominal wage set by household $j$. Then demand for this household's labor is

$$
H_{t}(j)=\left(\frac{W_{t}(j)}{W_{t}}\right)^{-v_{L}} H_{t}
$$

where the aggregate wage index $W_{t}$ is given by

$$
W_{t}=\left(\int_{0}^{1} W_{t}(j)^{1-v_{L}} d j\right)^{1 /\left(1-v_{L}\right)} .
$$

Household $j$ maximizes its expected lifetime utility drawn from consumption $C_{t}(j)$ relative to a habit stock, real money balances $M_{t}(j) / P_{t}$, and leisure:

$$
\mathbf{E}_{t}\left[\sum_{k=0}^{\infty} \beta^{k}\left(\log \left(C_{t+k}(j)-\gamma h C_{t+k-1}\right)+\frac{\chi_{M}}{\mu}\left(\frac{M_{t+k}(j)}{\gamma^{t+k} P_{t+k}}\right)^{\mu}-\chi_{H} \frac{H_{t+k}(j)^{1+\tau}}{1+\tau}\right)\right],
$$

where $\beta$ is the discount factor, and $\tau$ is the inverse of the intertemporal substitution elasticity of hours. The habit persistence in consumption is governed by $h$ while $\gamma$ denotes the growth of the aggregate output by which it is ensured that the economy evolves along a balanced growth path. Note 
here that the habit stock refers to the entire economy's habit consumption rather than individual habit consumption.

The consumption bundle of household $j$ is given as a constant elasticity of substitution (CES) aggregate of oil $O_{C, t}(j)$ consumption and nonoil core consumption $Z_{t}(j)$ :

$$
C_{t}(j)=\left[\omega_{o}^{1 / \phi_{c}} O_{C, t}(j)^{1-1 / \phi_{c}}+\left(1-\omega_{o}\right)^{1 / \phi_{c}} Z_{t}(j)^{1-1 / \phi_{c}}\right]^{\phi_{c} /\left(\phi_{c}-1\right)},
$$

where $\phi_{c}$ is the intratemporal elasticity of substitution between oil and core consumption, and $\omega_{o}$ denotes the share of oil consumption. Oil is directly consumed as fuel for heating and transportation. The core consumption is again defined as a CES aggregate of domestically produced goods (Home goods) $C_{H, t}(j)$, and imported goods (Foreign goods) $C_{F, t}(j)$ :

$$
Z_{t}(j)=\left[\left(1-\omega_{F}\right)^{1 / \phi_{z}} C_{H, t}(j)^{1-1 / \phi_{z}}+\omega_{F}^{1 / \phi_{z}} C_{F, t}(j)^{1-1 / \phi_{z}}\right]^{\phi_{z} /\left(\phi_{z}-1\right)},
$$

where $\phi_{z}$ denotes the intratemporal elasticity of substitution between Home and Foreign goods, and $\omega_{F}$ is the import share. For any given level of consumption bundle $C_{t}(j)$ as a result of household utility maximization behavior, household $j$ tries to maximize the profit in purchasing such a consumption bundle. Let $P_{o, t}$ and $P_{Z, t}$ denote the prices of oil and core consumption goods, respectively. We further define $P_{t}$ as the price of the composite consumption good. Then the consumption bundle is composed of oil and core consumption goods:

$$
O_{C, t}(j)=\omega_{o}\left(\frac{P_{o, t}}{P_{t}}\right)^{-\phi_{c}} C_{t}(j), \quad Z_{t}(j)=\left(1-\omega_{o}\right)\left(\frac{P_{Z, t}}{P_{t}}\right)^{-\phi_{c}} C_{t}(j) .
$$

The core consumption goods basket $Z_{t}(j)$ is purchased in a similar fashion:

$$
C_{H, t}(j)=\left(1-\omega_{F}\right)\left(\frac{P_{H, t}}{P_{z, t}}\right)^{-\phi_{z}} Z_{t}(j), \quad C_{F, t}(j)=\omega_{F}\left(\frac{P_{F, t}}{P_{Z, t}}\right)^{-\phi_{z}} Z_{t}(j)
$$

where $P_{H, t}$ and $P_{F, t}$ are the prices of Home and Foreign goods, respectively. The price of the composite consumption good $P_{t}$, namely, the consumptionbased price index (CPI), can be written as

$$
P_{t}=\left[\omega_{o} P_{o, t}^{1-\phi_{c}}+\left(1-\omega_{o}\right) P_{Z, t}^{1-\phi_{c}}\right]^{1 /\left(1-\phi_{c}\right)},
$$

where the CPI for core consumption is given by

$$
P_{Z, t}=\left[\left(1-\omega_{F}\right) P_{H, t}^{1-\phi_{z}}+\omega_{F} P_{F, t}^{1-\phi_{z}}\right]^{1 /\left(1-\phi_{z}\right)} .
$$

Household $j$ enters period $t$ with domestic portfolio of Arrow securities $D_{t}(j)$ that pays out one unit of domestic currency in a particular state; foreign-currency bond $B_{t-1}^{*}(j)$ that pays one unit for sure; nominal money balances $M_{t-1}(j)$; and a stock of capital $K_{t-1}(j) .{ }^{1}$ In period $t$, the household pays a lump-sum tax $T_{t}(j)$, earns income from selling labor and renting 
capital to firms, receives dividends (profits) $\Pi_{t}(j)$ from monopolistic firms, and adjusts the balances on domestic portfolio, foreign-currency bond, and nominal money balances. In particular, acquiring the position on foreigncurrency bond entails the premium; that is, households need to pay more than the international price to purchase bonds. Now we can write the budget constraints that domestic households face each period as

$$
\begin{aligned}
P_{t}\left(C_{t}(j)+\right. & \left.I_{t}(j)\right)+\mathbf{E}_{t}\left[Q_{t, t+1} D_{t+1}(j)\right]+M_{t}(j)+\frac{e_{t} B_{t}^{*}(j)}{R_{t}^{*} \Theta\left(\frac{e_{t} B_{t}^{*}}{P_{X, t} X_{t}}\right)} \\
\leq & W_{t}(j) H_{t}(j)+R_{t}^{K} K_{t-1}(j)+D_{t}(j)+M_{t-1}(j)+e_{t} B_{t-1}^{*}(j) \\
& +\prod_{t}(j)-T_{t}(j),
\end{aligned}
$$

where $Q_{t, t+1}$ is the stochastic discount factor used for evaluating consumption streams, $R_{t}^{K}$ is the nominal rental rate of capital, $e_{t}$ is the nominal exchange rate, and $R_{t}^{*}$ is the nominal international interest rate. Had it not been for the foreign bond premium, households would have paid $1 / R_{t}^{*}$ as the price of the foreign bond. In reality, however, they should pay the premium $\Theta\left(e_{t} B_{t}^{*} / P_{X, t} X_{t}\right)$ to purchase the foreign bond. The functional form suggests that the premium is related to the ratio of the outstanding foreign debt to nominal value of exports, a measure for healthiness of the economy. That is, the premium increases as foreign debt ratio increases. For simplicity, we further assume that $\Theta(\cdot)$ show constant elasticity $\kappa$. In this case, the premium of foreign bond prices changes $\kappa$ percent when the foreign debt ratio changes by 1 percent. The international interest rate, inverse of the foreign bond price, is assumed to follow a stochastic process. Households accumulate capital according to

$$
K_{t}(j)=(1-\delta) K_{t-1}(j)+I_{t}(j),
$$

where $\delta$ is the capital depreciation rate. Since we assume that there is no adjustment cost for investment, the consumption good and the investment good are interchangeable. Under the assumption of the complete domestic asset market, households entertain the perfect risk-sharing, which implies the same level of consumption across household regardless of the labor and rental income they receive each period; therefore, we can drop the notation $j$ from consumption and investment. The household decision problem regarding consumption, savings, and investment can be characterized by the following Euler equations:

$$
\begin{aligned}
& \mathbf{E}_{t}\left[\beta\left(\frac{C_{t+1}-\gamma h C_{t}}{C_{t}-\gamma h C_{t-1}}\right)^{-1} R_{t} \frac{P_{t}}{P_{t+1}}\right]=1 \\
& \mathbf{E}_{t}\left[\beta\left(\frac{C_{t+1}-\gamma h C_{t}}{C_{t}-\gamma h C_{t-1}}\right)^{-1} \Theta\left(\frac{e_{t} B_{t}^{*}}{P_{X, t} X_{t}}\right) R_{t}^{*} \frac{e_{t+1}}{e_{t}} \frac{P_{t}}{P_{t+1}}\right]=1
\end{aligned}
$$




$$
\mathbf{E}_{t}\left[\beta\left(\frac{C_{t+1}-\gamma h C_{t}}{C_{t}-\gamma h C_{t-1}}\right)^{-1}\left(\frac{R_{t+1}^{\kappa}}{P_{t+1}}+1-\delta\right)\right]=1,
$$

where $R_{t}={ }_{t}\left[Q_{t, t+1}\right]^{-1}$. The first and second equations are asset pricing equations regarding the real return on the purchase of domestic and foreign bonds, while the third equation is related to the return on the investment on the physical capital.

As in Erceg, Henderson, and Levin (2000) we assume that wage setting is subject to a nominal rigidity à la Calvo (1983) and Yun (1996). While each household can set the wage $W_{t}(j)$ of its own labor service by entertaining its monopoly power, only a fraction $\left(1-\theta_{L}\right)$ of households are entitled chances for full optimization at any given period, independent of the time elapsed since the last adjustment. Thus, in each period a measure $\left(1-\theta_{L}\right)$ of households reoptimizes its wage, while a fraction $\theta_{L}$ adjusts its wage according to a partial indexation rule:

$$
W_{t+k}(j)=\Gamma_{W, t}^{k} W_{t}(j),
$$

where $\Gamma_{W, t}^{k}=\left(\gamma \bar{\pi}^{\left(1-\xi_{L}\right)} \pi_{t+k-1}^{\xi_{L}}\right) \Gamma_{W, t}^{k-1}$. That is, households who cannot reoptimize wages update them by considering a weighted average of past CPI inflation $\pi_{t-1}$ and the inflation target $\bar{\pi}$ set by the monetary authority.

Household $j$, who has the chance to reoptimize its wage at period $t$, chooses $\tilde{W}_{t}(j)$ (and $\tilde{H}_{t}(j)$, accordingly) to maximize the lifetime utility subject to the labor demand (1) and the updating rule for the nominal wage (2). The firstorder condition can be written as

$\mathbf{E}_{t}\left[\sum_{k=0}^{\infty}\left(\beta \theta_{L}\right)^{k}\left(\left(\frac{1}{v_{L}}\right) \frac{\tilde{W}_{t}(j) \Gamma_{W, t}^{k}}{P_{t+k}}\left(C_{t+k}-\gamma h C_{t+k-1}\right)^{-1}-\chi_{H} \tilde{H}_{t+k}(j)^{\tau}\right) \tilde{H}_{t+k}(j)\right]=0$.

\subsubsection{Domestic Firms}

There is a continuum of monopolistically competitive Home goodsproducing firms indexed by $i \in[0,1]$. Home goods producers have identical CES production functions that use labor, capital service, and oil as inputs:

$$
Y_{H, t}(i)=\zeta_{H, t}\left[(1-\alpha)^{1 / \phi_{H}}\left(\gamma^{t} N_{H, t}(i)\right)^{1-1 / \phi_{H}}+\alpha^{1 / \phi_{H}}\left(K_{H, t}(i)^{1-\eta} O_{H, t}(i)^{\eta}\right)^{1-1 / \phi_{H}}\right]^{\phi_{H} /\left(\phi_{H}-1\right)} \text {, }
$$

where $N_{H, t}(i)$ and $K_{H, t}(i)$ are the labor and capital input hired by firm $i, O_{H, t}(i)$ is oil used in the production of the variety $i$, and $\zeta_{H, t}$ represents a stationary productivity shock in the Home goods sector that is common to all firms. The aforementioned production specification requires that the oil input being combined with the capital and the unit elasticity of substitution between oil and capital is assumed. Parameter $\phi_{H}$ governs the elasticity of substitution between labor and capital-oil aggregate in production, $\alpha$ denotes the share of oil-capital aggregator, and $\eta$ is the share of oil in oil-capital aggregator. While firms behave monopolistically in the goods market, they buy inputs competitively in the factor market. Given input prices $W_{t}, R_{t}^{K}$, and $P_{o, t}$ the cost minimization gives us 


$$
\begin{gathered}
\frac{R_{t}^{K}}{P_{o, t}}=\frac{1-\eta}{\eta} \frac{O_{H, t}(i)}{K_{H, t}(i)} \\
\left(\frac{W_{t}}{\gamma^{t} P_{o, t}}\right)^{\phi_{H}}=\frac{1-\alpha}{\alpha} \eta^{-\phi_{H}} \frac{K_{H, t}(i)}{\gamma^{t} N_{H, t}(i)}\left(\frac{O_{H, t}(i)}{K_{H, t(i)}}\right)^{\eta=\phi_{H}-\eta \phi_{H}} .
\end{gathered}
$$

That is, the oil-capital ratio and labor-capital ratio are constant across firms. Therefore, the nominal marginal cost of production is given by

$$
M C_{t}=\frac{1}{\zeta_{H, t}}\left[(1-\alpha)\left(\frac{W_{t}}{\gamma^{t}}\right)^{1-\phi_{H}}+\alpha\left\{\left(\frac{P_{o, t}}{\eta}\right)^{\eta}\left(\frac{R_{t}^{K}}{1-\eta}\right)^{1-\phi_{H}}\right\}^{1-\eta}\right]^{1 /\left(1-\phi_{H}\right)},
$$

which implies that the marginal cost of production is the same across all firms.

Price setting is again subject to a nominal rigidity à la Calvo (1983) and Yun (1996). In each period only a fraction $\left(1-\theta_{H}\right)$ of firms can fully optimize their output prices. The remaining firms of fraction $\theta_{H}$ can only adjust the price according to a partial indexation scheme:

$$
P_{H, t+k}(i)=\Gamma_{H, t}^{k} P_{H, t}(i)
$$

where $\Gamma_{H, t}^{k}=\left(\bar{\pi}^{\left(1-\xi_{H}\right)} \pi_{H, t+k-1}^{\xi_{H}}\right) \Gamma_{H, t}^{k-1}$ and $\pi_{H, t}=P_{H, t} / P_{H, t-1}$. For firms who do not have chances to reoptimize prices, the price adjustment factor is a weighted average between the past inflation of Home goods $\pi_{H, t-1}$ and the target inflation rate $\bar{\pi}$. The parameter $\xi_{H}$ captures the degree of indexation in the economy. For firm $i$, who has the opportunity to reoptimize the output price, it chooses $\tilde{P}_{H, t}(i)$ to maximize the expected profit

$$
\mathbf{E}_{t}\left[\sum_{k=0}^{\infty} \theta_{H}^{k} \Lambda_{t, t+k}\left(\Gamma_{H, t}^{k} \tilde{P}_{H, t}(i)-M C_{t+k}\right) \tilde{Y}_{H, t+k}(i)\right]
$$

subject to the demand function:

$$
\tilde{Y}_{H, t}(i)=\left(\frac{\tilde{P}_{H, t}(i)}{P_{H, t}}\right)^{-v_{H}} Y_{H, t} .
$$

Hence, the first-order condition is

$$
\mathbf{E}_{t}\left[\sum_{k=0}^{\infty} \theta_{H}^{k} \Lambda_{t, t+k} \tilde{Y}_{H, t+k}(i)\left(\Gamma_{H, t}^{k} \tilde{P}_{H, t}(i)-\frac{v_{H}}{v_{H}-1} M C_{t+k}\right)\right]=0 .
$$

Note that $\Lambda_{t, t+k}$ is the marginal value of a unit of the consumption good to households, which is treated as exogenous by the firm:

$$
\Lambda_{t, t+k}=\beta^{k} \frac{P_{t}}{P_{t+k}}\left(\frac{C_{t}-\gamma h C_{t-1}}{C_{t+k}-\gamma h C_{t+k-1}}\right) .
$$

Given the price charged by a firm $i$, its profit is given by

$$
\Pi_{t}(i)=P_{H, t}(i) Y_{H, t}(i)-W_{t} N_{H, t}(i)-R_{t}^{K} K_{H, t}(i)-P_{o, t} O_{H, t}(i) .
$$




\subsubsection{The Foreign Economy}

The foreign demand for Home goods is given by

$$
C_{H, t}^{*}=\omega_{H}^{*}\left(\frac{P_{H, t}^{*}}{P_{F, t}^{*}}\right)^{-\phi^{*}} C_{t}^{*}
$$

where $\omega_{H}^{*}$ denotes the import share in the consumption basket of foreign agents and $\phi^{*}$ captures the intratemporal elasticity of substitution between Foreign and Home goods in the foreign economy. The foreign consumption $C_{t}^{*}$ is exogenously given and follows a stochastic process.

We assume the law of one price (LOP) holds for Home goods. That is, the domestic firms cannot discriminate across markets in terms of prices. This also holds for imported Foreign goods except oil:

$$
P_{H, t}^{*}=\frac{P_{H, t}}{e_{t}}, \quad P_{F, t}=e_{t} P_{F, t}^{*}
$$

We can define the real exchange rate as:

$$
s_{t}=\frac{e_{t} P_{F, t}^{*}}{P_{t}} .
$$

Note that the price of consumption bundle of foreign agents is dominated by $P_{F, t}^{*}$ rather than $P_{t}^{*}$ because home country is assumed to be a small open economy; therefore the import share of the foreign economy $\omega_{H}^{*}$ is negligible. The domestic real price of oil is given by

$$
\frac{P_{o, t}}{P_{t}}=s_{t} \frac{P_{o, t}^{*}}{P_{F, t}^{*}} \zeta_{o, t}
$$

where $P_{o, t}^{*}$ is the foreign currency price of oil abroad. The pass-through of oil prices is incomplete in the sense that $\zeta_{o, t}$ signifies the deviations from the law of one price in the oil price. This deviation $\zeta_{o, t}$ is assumed to follow a stochastic process. The real international oil price $P_{o, t}^{*} / P_{F, t}^{*}$ also follows a stochastic process.

\subsubsection{Monetary Authority}

Monetary policy is described by an interest rate feedback rule of the form

$$
R_{t}=R_{t-1}^{\rho_{R}} \bar{R}_{t}^{1-\rho_{R}} \exp \left(\epsilon_{R, t}\right)
$$

where $\epsilon_{R, t}$ is a monetary policy shock and $\bar{R}_{t}$ is the nominal target interest rate. Monetary authority sets its target in responding to inflation and deviations of output growth rate from its trend:

$$
\bar{R}_{t}=\overline{r \pi}\left(\frac{\pi_{t}}{\bar{\pi}}\right) \psi_{\pi}\left(\frac{Y_{t}}{\gamma Y_{t-1}}\right) \psi_{y}
$$

where $\bar{r}$ is real interest rate at the steady state. 


\subsubsection{Aggregation and Equilibrium}

We abstract from the government spending. We further assume that the government passively runs a balanced budget every period:

$$
\int_{0}^{1}\left(M_{t}(j)-M_{t-1}(j)\right) d j+\int_{0}^{1} T_{t}(j) d j=0 .
$$

The goods market, the labor market, and the capital market clear

$$
\begin{aligned}
Y_{H, t} & =\int_{0}^{1}\left(C_{H, t}(j)+C_{H, t}^{*}(j)+I_{H, t}(j)\right) d j \\
H_{t} & =\int_{0}^{1} N_{H, t}(i) d i \\
\int_{0}^{1} K_{t-1}(j) d j & =\int_{0}^{1} K_{H, t}(i) d i .
\end{aligned}
$$

We consider the symmetric equilibrium where households and firms make the same decision when available. Combining equilibrium conditions, the budget constraint of the government, and the aggregate budget constraint of households, we get the following dynamics of foreign bond holdings:

$$
\frac{e_{t} B_{t}^{*}}{R_{t}^{* \Theta} e_{t} B_{t}^{* /}\left(P_{X, t} X_{t}\right)}=e_{t} B_{t-1}^{*}+P_{X, t} X_{t}-P_{M, t} M_{t} .
$$

As noted before, imports consist of oil and Foreign goods for consumption and investment while domestically produced goods are the only export of the economy. Therefore, the aggregate nominal value of exports and imports are defined as

$$
\begin{aligned}
P_{X, t} X_{t} & =P_{H, t} C_{H, t}^{*} \\
P_{M, t} M_{t} & =s_{t} P_{t}\left(C_{F, t}+I_{F, t}\right)+e_{t} P_{o, t}^{*} O_{t},
\end{aligned}
$$

where $X_{t}$ and $M_{t}$ denote exports and imports, respectively. Total oil imports are the sum of oil for direct consumption and that for production, $O_{t}=O_{C, t}$ $+O_{H, t}$. We can also write the nominal gross domestic product (GDP) as

$$
P_{Y, t} Y_{t}=P_{t}\left(C_{t}+I_{t}\right)+P_{X, t} X_{t}-P_{M, t} M_{t},
$$

where $P_{Y, t}$ denotes the implicit output deflator.

\subsubsection{Steady State}

The model is equipped with deterministic trend. Hence, we first detrend variables to define the steady state. All price and wage variables are written as relative prices to the Home CPI $P_{t}$. Real variables with trend are to be divided by $\gamma^{t}$. At the steady state after detrending, all relative prices and the real wage are normalized to one for computational convenience. 


\subsection{Estimation Methods}

This section consists of two parts. First, we briefly discuss how to estimate and evaluate the model with Bayesian approach. With the state space representation of the model, we can estimate the model within Bayesian estimation frameworks, so-called Metropolis-Hastings algorithm with Kalman filter. See An and Schorfheide (2007) for a review. Also, we introduce the DSGE-VAR framework developed in Del Negro and Schorfheide (2004) and Del Negro et al. (2007). The DSGE-VARs are useful to check how DSGE models are misspecified. This framework tries to find out the optimal weight between two approaches, DSGEs and VARs, that fit data best. Next, we explain the data used in our analysis.

\subsubsection{Estimation and Evaluation of DSGE Models}

To establish an estimable representation, we first log-linearize the model around its nonstochastic steady state. Several solution algorithms of the linearized rational expectations system are available; for instance, Blanchard and Kahn (1980), Uhlig (1999), and Sims (2002). With the help of the solution algorithm, the log-linearized system can be written as an autoregressive model in a vector of variables:

$$
s_{t}=\Phi^{(s)}(\theta) s_{t-1}+\Phi^{(\varepsilon)}(\theta) \varepsilon_{t},
$$

where $s_{t}$ denotes the vector of model variables in log-deviation from the steady state, and $\varepsilon_{t}$ is the vector of innovations to shock processes. The coefficients $\Phi^{(s)}(\theta)$ and $\Phi^{(\varepsilon)}(\theta)$ are conformable matrices whose values are dependent on the values of DSGE model parameters $\theta$. Given that some of the variables in $s_{t}$ are not observable, we can treat (4) as the transition equation of a state space representation. Once we define a vector of observables, $y_{t}$, we can set up measurement equations:

$$
y_{t}=\Theta^{(0)}(\theta)+\Theta^{(s)}(\theta) s_{t} .
$$

More specifically, we assume that the time period $t$ in the model corresponds to one quarter and that the following observations are available for estimation: quarter-to-quarter per capita GDP growth rate, annualized nominal interest rate, annualized quarter-to-quarter core CPI inflation rate, annualized quarter-to-quarter hourly wage inflation, quarter-to-quarter nominal exchange rate depreciation, international oil prices relative to domestic price level, and quarter-to-quarter growth rate of oil imports. The system matrices, $\Phi^{(s)}, \Phi^{(\varepsilon)}, \Theta^{(0)}$, and $\Theta^{(\varepsilon)}$, in the state space representation, (4) and (5), are given as highly nonlinear functions of the DSGE model parameters $\theta$.

While DSGE models are popular among the economists because of their microfoundations, the empirical performance is not so successful until Christiano, Eichenbaum, and Evans (2005) and Smets and Wouters (2003). On the contrary, VARs are widely used in empirical macroeconomics and 
considered as benchmarks for evaluating dynamic economies due to better fit of the data and forecasting power. Del Negro and Schorfheide (2004) and Del Negro et al. (2007) investigate possible connections between DSGE models and VARs. We first briefly mention the Bayesian approach to estimate the state space representation of DSGE models as in (4) and (5). Then we proceed further on the DSGE-VAR procedure.

The Bayesian approach is widely used in the estimation of DSGE models. The main advantage is that it has a systematic way to incorporate information that is available but at the same time tricky or even impossible to formally construct the likelihood. The likelihood information $p(Y \mid \theta)$ contained in the data used for estimation is extracted via Kalman filter in the state space representation, and the information that is informally available is summarized as the prior distribution $p(\theta)$. This informal information can include results from related literature that employs other data sets and models. The Bayes theorem provides the basic insight how to update the prior belief on parameters with the information contained in the data; that is, the likelihood. With well-specified prior distribution, the posterior distribution $p(\theta \mid Y)$ can be simulated through the Markov-chain Monte Carlo (MCMC) procedure.

Another convenient procedure in Bayesian analysis is the model selection. The posterior odd ratio is a key statistic in selecting a model among a series of competing models. We can just choose one with the highest posterior odds. With equal prior probabilities assigned to each model, the posterior odds are not different from the ratio of the marginal data densities (or the marginal likelihood, equivalently) $p(Y)$ across models. Therefore, it suffices to have a procedure to evaluate the marginal data density given the draws from the posterior distribution. This can be achieved by Geweke's (1999) modified harmonic mean estimator.

Given the state space representation of DSGE models, it is not difficult to imagine that there exists a tight link between DSGE models and VARs. That is, the cross equation relationships restricted by DSGE models can be imposed on VAR parameters; therefore we can expect a better performance of VARs with this priori restriction. Del Negro and Schorfheide (2004) introduce the DSGE-VAR $(\lambda)$ procedure from this perspective. The hyper parameter $\lambda$ governs the tightness of the priori restrictions from DSGE models. When the DSGE prior weight $\lambda$ approaches infinity, the VAR parameters are tightly restricted by the cross equation restrictions from DSGE models. When the DSGE prior weight $\lambda$ approaches zero, on the contrary, the DSGE model imposes no restriction on the VAR parameters and the estimation procedure behaves like an unrestricted VAR model. Hence, by changing the value of the hyper parameter $\lambda$ we can generate a series of VAR models whose parameter restrictions based on a DSGE model have different tightness.

Another interpretation of DSGE-VARs tackles misspecification issues of 
DSGE models. As noted before, DSGE models are well accepted among the economists since their modeling is based on economic theory and impulse response analysis is straightforward. However, restrictions derived from DSGE models are often too tight to match the data, and hence the empirical performance is usually far from satisfactory. Del Negro et al. (2007) point out that the data generating process of a VAR is decomposed into the DSGE model part and its possible misspecifications, and this misspecification can be modeled in a Bayesian framework. The same hyper parameter $\lambda$ now refers to the degree of misspecification. As $\lambda$ moves away from the infinity where only DSGE models are allowed as correct specification, the flexibility in describing the data increases. If we can find out the "optimal" value, namely $\hat{\lambda}$, it can be used to evaluate the specification of the DSGE model. In short, the larger $\hat{\lambda}$ is, the smaller is the misspecification of the DSGE model and a lot of weight should be placed on its implied restrictions.

As discussed before, we can consider a series of specifications in terms of the hyper parameter $\lambda$ given a DSGE model. Noting that the best model can be selected using the posterior odds ratio in Bayesian analysis, the "optimal" weight on DSGE prior $\hat{\lambda}$ can be found by maximizing the marginal likelihood with respect to $\lambda$. When $\hat{\lambda}$ is chosen according to the posterior odds criterion, a comparison between DSGE-VAR $(\hat{\lambda})$ and DSGE model impulse responses can reveal important insights about the misspecification of the DSGE model. While DSGE model impulse response is well defined, impulse responses of DSGE-VAR $(\hat{\lambda})$ needs careful treatment. To obtain a proper impulse response, we should align DSGE-VAR $(\hat{\lambda})$ along with structural shocks of the DSGE model. The details of this procedure can be found in Del Negro and Schorfheide (2004).

\subsubsection{Data}

Most of the data are obtained through KOSIS (Korean statistical information service), ${ }^{2}$ maintained by Korea National Statistical Office and ECOS (Economic statistics system), ${ }^{3}$ maintained by the Bank of Korea. Seasonally adjusted real GDP is divided by population fifteen years and older and its growth rate is calculated as 100 times the first difference in logs. The interest rate is the overnight call rate. The core inflation rate is calculated from core CPI as 400 times the first difference in logs. The nominal hourly wage is obtained by dividing total wage by total hours worked and its inflation is again calculated as 400 times the first difference in logs. The nominal exchange rate depreciation is calculated as 100 times the first difference in logs of the effective exchange rate published by the Bank of International Settlement (BIS). The international oil price relative to domestic price level is obtained by dividing WTI crude oil spot price by CPI and being nor- 
malized after taking logs. Finally, the crude oil import is obtained from Korea National Oil Corporation ${ }^{4}$ and then seasonally adjusted by the X12 method, available from EViews. Per capita term is obtained by dividing it by population fifteen years and older, and then quarter-to-quarter growth rate is calculated as 100 times the first difference in logs. Data are available for 1993:Q2 to 2008:Q4.

\subsection{Empirical Results}

We begin this section by explaining the specification of prior distributions of structural parameters of the DSGE model. In the following discussion on the "optimal" DSGE prior weight, we also consider two variants of our baseline DSGE model. One lacks oil in consumption basket and the other excludes oil from inputs of production. We discuss how a fit changes as we move away from our baseline model. We also look into impulse response functions from our DSGE models and compare them with those from "optimal" DSGE-VARs. Finally, we investigate the behavior of deviations from the law of one price in domestic oil prices and the oil price pass-through as the international crude oil prices surges in mid-2000s.

In what follows, we use DYNARE for estimation of both DSGE models and DSGE-VARs. For each specification we generate 125,000 draws from posterior distributions, and the first 25,000 draws are discarded for convergence of Markov-chain.

\subsubsection{Prior Distribution}

Prior distribution in Bayesian analysis plays an important role in the estimation of DSGE models. By specifying them, we express our own view on plausible parameter values. Actually this process reweights the information contained in the data that are used in actual estimation. That is, we can incorporate extra information that is possibly missing in estimation samples and is developed in the related literature.

To begin with, we calibrate several parameter values that are not identified in our representation. First, the substitution elasticity across differentiated labor $v_{L}$ that governs wage markup is set to 9 as in Medina and Soto (2005). The price markup parameter $v_{H}$ is not present in our linearized model. Noting that our model abstracts from government spending, we set the steadystate consumption-output ratio as 0.66 , which stems from the average ratio of the sum of consumption and government expenditure to GDP in our sample. The steady-state investment-output ratio is 0.32 and the steady-state export share is 0.38 , according to our sample. From these ratios, we can derive other big ratios using steady-state relationships.

Table 9.2 lists the marginal prior distributions for the structural param-

4. See http://www.petronet.or.kr. 


\begin{tabular}{|c|c|c|c|c|c|}
\hline Name & Domain & Density & Mean & $\begin{array}{l}\text { Standard } \\
\text { deviation }\end{array}$ & Description \\
\hline$\alpha$ & {$[0,1)$} & Beta & 0.300 & 0.100 & Capital-oil share in production \\
\hline$\eta$ & {$[0,1)$} & Beta & 0.500 & 0.200 & Oil share in capital-oil \\
\hline$\delta$ & {$[0,1)$} & Beta & 0.015 & 0.002 & Depreciation rate \\
\hline$\tau$ & $\mathbf{R}^{+}$ & Gamma & 1.000 & 0.750 & (inverse) EIS of labor \\
\hline$h$ & {$[0,1)$} & Beta & 0.500 & 0.200 & Habit persistence \\
\hline$\kappa$ & $\mathbf{R}^{+}$ & Gamma & 0.010 & 0.005 & Elasticity: Risk premium \\
\hline$\varphi_{Z}$ & $\mathbf{R}^{+}$ & Gamma & 0.300 & 0.200 & Elasticity: $\mathrm{H} / \mathrm{F}$ goods consumption \\
\hline$\varphi^{*}$ & $\mathbf{R}^{+}$ & Gamma & 1.000 & 0.400 & $\begin{array}{l}\text { Elasticity: } \mathrm{H} / \mathrm{F} \text { goods in foreign } \\
\text { consumption }\end{array}$ \\
\hline$\varphi_{C}$ & $\mathbf{R}^{+}$ & Gamma & 0.330 & 0.150 & Elasticity: Oil and core consumption \\
\hline$\varphi_{H}$ & $\mathbf{R}^{+}$ & Gamma & 0.500 & 0.300 & $\begin{array}{l}\text { Elasticity: Oil-capital and labor input } \\
\text { of production }\end{array}$ \\
\hline$\theta_{H}$ & {$[0,1)$} & Beta & 0.700 & 0.100 & Calvo on price \\
\hline$\theta_{L}$ & {$[0,1)$} & Beta & 0.700 & 0.150 & Calvo on wage \\
\hline$\xi_{H}$ & {$[0,1)$} & Beta & 0.500 & 0.200 & Price indexation \\
\hline$\xi_{L}$ & {$[0,1)$} & Beta & 0.500 & 0.200 & Wage indexation \\
\hline$\psi_{\pi}$ & $\mathbf{R}^{+}$ & Gamma & 1.500 & 0.200 & Responsiveness on inflation \\
\hline$\psi_{y}$ & $\mathbf{R}^{+}$ & Gamma & 0.500 & 0.250 & Responsiveness on output \\
\hline$\rho_{R}$ & {$[0,1)$} & Beta & 0.750 & 0.100 & Persistence: Interest rate \\
\hline$\gamma^{(Q)}$ & $\mathbf{R}$ & Normal & 0.750 & 0.300 & Growth rate \\
\hline$r^{(A)}$ & $\mathbf{R}^{+}$ & Gamma & 0.500 & 0.200 & Steady-state real interest rate \\
\hline$\pi^{(A)}$ & $\mathbf{R}^{+}$ & Gamma & 3.000 & 2.000 & Target inflation rate \\
\hline$\omega_{F}$ & {$[0,1)$} & Beta & 0.350 & 0.100 & Weight on foreign good consumption \\
\hline$\omega_{\mathrm{o}}$ & {$[0,1)$} & Beta & 0.100 & 0.050 & Weight on oil consumption \\
\hline$\rho_{A}$ & {$[0,1)$} & Beta & 0.700 & 0.150 & Persistence: Technology \\
\hline$\rho_{o}$ & {$[0,1)$} & Beta & 0.700 & 0.150 & Persistence: Oil price pass-through \\
\hline$\rho_{o^{*}}$ & {$[0,1)$} & Beta & 0.700 & 0.150 & Persistence: Foreign oil price \\
\hline$\rho_{R^{*}}$ & {$[0,1)$} & Beta & 0.700 & 0.150 & Persistence: Foreign interest rate \\
\hline$\rho_{\pi^{*}}$ & {$[0,1)$} & Beta & 0.700 & 0.150 & Persistence: Foreign inflation \\
\hline$\rho_{C^{*}}$ & {$[0,1)$} & Beta & 0.700 & 0.150 & Persistence: Foreign consumption \\
\hline$\sigma_{R}$ & $\mathbf{R}^{+}$ & InvGamma & 0.010 & 2 & StDev: Monetary policy \\
\hline$\sigma_{A}$ & $\mathbf{R}^{+}$ & InvGamma & 0.150 & 2 & StDev: Technology \\
\hline$\sigma_{o}$ & $\mathbf{R}^{+}$ & InvGamma & 0.150 & 2 & StDev: Oil-price pass-through \\
\hline $\begin{array}{l}\sigma_{o} \\
\sigma_{o^{*}}\end{array}$ & $\mathbf{R}^{+}$ & InvGamma & 0.150 & 2 & StDev: Foreign oil price \\
\hline$\sigma_{R^{*}}$ & $\mathbf{R}^{+}$ & InvGamma & 0.050 & 2 & StDev: Foreign interest rate \\
\hline$\sigma_{\pi^{*}}$ & $\mathbf{R}^{+}$ & InvGamma & 0.050 & 2 & StDev: Foreign inflation \\
\hline$\sigma_{C^{*}}$ & $\mathbf{R}^{+}$ & InvGamma & 0.050 & 2 & StDev: Foreign consumption \\
\hline
\end{tabular}

Notes: For the inverse-gamma distribution, values in the standard deviation column denote degrees of freedom.

eters of the DSGE model. In general, the prior distributions used in this study are quite diffuse. As usual, the rule of thumb in choosing the distribution family for each parameter is the shape of the support. Parameters that have limits on both ends, usually confined between 0 and 1 , follow the beta distribution. For those with positive unbound support we specify the gamma 
distribution, with the exception of standard deviations of shock processes for which inverse gamma distributions are assumed. Unbounded parameters are specified as normal distributions. The share of oil-capital aggregator in production $\alpha$ has a mean of 0.3 , the usual capital share of an economy. With standard deviation $0.1,90$ percent coverage is $[0.15,0.48]$. The oil share in oil-capital aggregator $\eta$ is centered at 0.5 since no primitive estimate is available. The quarterly depreciation rate $\delta$ has a mean of 0.015 , implying 6 percent annual depreciation. Inverse of intertemporal substitution elasticity of labor $\tau$ has a mean of 1 and standard deviation of 0.75 , whose 90 percent coverage is $[0.15,2.46]$. Without preference shock as in our model, this parameter is often estimated quite small and even negative with aggregate data. Due to lack of information on the habit persistence parameter $h$, it is centered at 0.5 and standard deviation 0.2 to have $[0.17,0.83]$ as 90 percent coverage. The elasticity of risk premium on foreign debt $\kappa$ has mean 0.01 with standard deviation 0.005 . The elasticity of substitution between Home and Foreign goods in core consumption $\phi_{z}$ has a relatively low mean of 0.3 and it is roughly around the calibrated value in the Bank of Korea model (BOKDSGE) by Kang and Park (2007). Its counterpart in foreign consumption $\phi^{*}$ is set to 1 . The elasticity between oil and core consumption $\phi_{C}$ is also low as 0.33 , since there is almost no substitute for oil in the Korean economy, especially when it comes to fuel for transportation. The elasticity between oil-capital aggregator and labor input of production $\phi_{H}$ is not obvious and hence it is set to 0.5 . For more discussion of the estimates of the elasticity of energy or oil with other inputs, see Backus and Crucini (2000). Calvo rigidity parameters for price $\theta_{H}$ and wage $\theta_{L}$ are equally set to have a mean of 0.7 . This value implies that prices and wages are reset every three quarters on average. Standard deviations for $\theta_{H}$ and $\theta_{L}$ are 0.1 and 0.15 , respectively. Hence, 90 percent coverage implies that prices are reset between 2.1 and 6.8 quarters and wages between 1.7 and 11.9 quarters. Price $\left(\xi_{H}\right)$ and wage $\left(\xi_{L}\right)$ indexation to past inflation are all centered at 0.5 and have a common standard deviation of 0.2 . Monetary policy parameters $\psi_{\pi}$ and $\psi_{y}$ are set to have means from Taylor's (1993) values, 1.5 and 0.5 , and 90 percent coverage, $[1.19,1.84]$ and $[0.17,0.97]$, respectively. We further specify weights on Foreign goods in core consumption $\omega_{F}$ and on oil in consumption $\omega_{o}$. They are centered at 0.35 and 0.1 , respectively. Persistence of shocks, $\left(\rho_{A}, \rho_{o}, \rho_{o^{*}}, \rho_{R^{*}}, \rho_{\pi^{*}}, \rho_{C^{*}}\right)$ have the same specification, mean of 0.75 and standard deviation of 0.15 .

\subsubsection{Model Selection and DSGE Prior Weight}

The main purpose of DSGE-VARs is to evaluate the (mis-)specification of DSGE models under consideration. To begin with, however, we investigate a direct estimation of structural parameters of our baseline model. Bayesian estimations of linearized DSGE models trace back to DeJong, Ingram, and Whiteman (2000); Landon-Lane (1998); and Schorfheide (2000); they use Markov-chain Monte Carlo (MCMC) algorithm for posterior simulator 
Table 9.3

The fit of the small open economy DSGE model

\begin{tabular}{llccc}
\hline Specification & $\lambda$ & Baseline & $\begin{array}{c}\text { No oil } \\
\text { consumption } \\
\omega_{0}=0\end{array}$ & $\begin{array}{c}\text { No oil in } \\
\text { production } \\
\eta=0\end{array}$ \\
\hline DSGE & & -1329.05 & -1499.42 & -1389.71 \\
DSGE-VAR & $\infty$ & -1278.47 & -1412.31 & -1387.04 \\
& 2 & -1220.09 & -1219.77 & -1293.64 \\
& 1.5 & -1198.91 & -1229.15 & -1204.30 \\
& 1.25 & -1206.11 & -1181.97 & -1183.42 \\
& 1 & -1171.12 & -1200.08 & -1206.92 \\
& 0.75 & -1185.81 & -1199.96 & -1211.15 \\
& 0.66 & -1155.76 & -1180.27 & -1184.79 \\
& 0.5 & -1132.41 & -1157.48 & -1155.61 \\
& 0.4 & -1155.80 & -1146.78 & -1136.48 \\
\hline
\end{tabular}

while Kalman filter provides exact likelihood computations. As noted previously, a unified framework for model selection within Bayesian framework, the posterior odds ratio, makes this approach quite popular. Here we consider two restrictions on the baseline model described in section 9.2. In our baseline economy, the entire volume of oil in domestic use is imported from foreign countries and a fraction of oil imports is directly consumed among households. The first restricted model tackles this point and assumes that oil is not included in the consumption basket ("No Oil Consumption"). On the contrary, oil is not used for production in the second restricted model ("No Oil in Production").

The first row of table 9.3 reports the log marginal likelihood of three models under consideration. The baseline model attains the highest marginal likelihood (-1329.05), followed by "No Oil in Production" (-1389.71) and then "No Oil Consumption" (-1499.42) models. That is, the baseline model best describes the data if these models are assigned the same prior probabilities. This result is somewhat expected given that both consumption and production motive of oil use in the Korean economy is sizable and significant, as seen in table 9.1. However, we should note that the marginal data density penalizes larger models like any information criterion and hence this result is not so obvious as it looks.

Now we turn our attention to DSGE prior weight; that is, DSGE-VARs. In practice, DSGE models have VAR representations with the truncation at a particular lag order. Due to short sample periods we restrict the lags in VARs to 2. This approximate VAR representation distinguishes DSGE-VARs from DSGE models even with infinite weight on DSGE priors, DSGE-VAR $(\infty)$. This discrepancy is obviously seen from differences between the first and the second rows in table 9.3. For each of three specifications, we try various values for the DSGE prior weight parameter $\lambda$ and report results in table 9.3. The DSGE-VARs with the baseline model attain the highest log marginal 
likelihood when $\lambda=0.5$ at -1132.4 , whereas those with other two restricted models do so when $\lambda=0.4$ (-1146.8 for "No Oil Consumption" and -1136.5 for "No Oil in Production"). That is, the "optimal" prior weight for the baseline economy is higher than those for the other two restricted models. This result again signifies that the degree of the misspecification in the baseline model is less than those in the other two restricted models because the baseline model would put more weight on the DSGE prior. Both from the comparison of log marginal likelihoods of DSGE models and the optimal weight of DSGE priors, we can now draw the same conclusion.

\subsubsection{Posterior Estimates}

Before proceeding with the posterior estimates of the DSGE model parameters, we should pay attention to the "optimal" weight for the baseline economy. With $\hat{\lambda}=0.5$, the best fit of the data is achieved by putting $1 / 3$ of the weight on the DSGE model and 2/3 on the VAR model; hence, there is still some room for improvement in the model specification. Del Negro et al. (2007) show that the Smets-Wouters model has around 1/2 weight in their DSGE-VAR analysis. As previously discussed, another interpretation of a DSGE-VAR is to extract prior information from a DSGE model for VAR coefficients; therefore, the posterior distribution of VAR coefficients can be expressed as the posterior distribution of DSGE model parameters, given the tightness of the prior from a DSGE model $\hat{\lambda}$. This refers to the posterior distribution of DSGE-VAR $(\hat{\lambda})$.

Table 9.4 reports posterior estimates from the DSGE model and DSGE$\operatorname{VAR}(\hat{\lambda})$ of the baseline model. In DSGE estimation, most of the parameters show information gain through likelihood; that is, the prior distribution is updated through the likelihood and results in the posterior distribution. A couple of parameters, $\delta$ and $\theta_{H}$, have roughly the same prior and posterior means. However, 90 percent coverage shrinks as they move to posterior distributions, which implies that likelihoods bring on some extra information. The capital share can be obtained from $\alpha(1-\eta)$ and its posterior mean is 0.201 for DSGE and 0.4142 for DSGE-VAR $(\hat{\lambda})$. The elasticity between oilcapital aggregator and labor input of production $\phi_{H}$ attains a very low posterior mean of 0.021 . This implies that the oil-capital aggregator and labor are not substitutable in production and hints a big difference in log marginal likelihoods between the baseline and "No Oil in Production" models. In $\operatorname{DSGE}-\operatorname{VAR}(\hat{\lambda})$ the posterior mean of this parameter is much bigger, 0.1750 , which implies more flexible substitution among inputs of production and results in smaller change in log marginal likelihoods when we abstract the production motive of the oil use. The model displays relatively high degrees of price $\theta_{H}$ and wage $\theta_{L}$ rigidities, 0.711 and 0.855 , with 3.5 and 6.9 quarters of duration, respectively. With DSGE-VAR $(\hat{\lambda})$, these durations are 5.4 and 3 quarters, respectively. The estimated slope of Phillips curve, $\beta /\left(1+\beta \xi_{H}\right)$, is around 0.63 both for DSGE and DSGE-VAR $(\hat{\lambda})$, and it is quite close to the 
Posterior estimates: Baseline model

\begin{tabular}{lcccr}
\hline & & & \multicolumn{2}{c}{ DSGE-VAR $(\hat{\lambda})$} \\
\cline { 3 - 5 } & Mean & DSGE & Mean & $90 \%$ interval \\
\hline$\alpha$ & 0.2287 & {$[0.2150,0.2431]$} & 0.4969 & {$[0.4268,0.5590]$} \\
$\eta$ & 0.1229 & {$[0.1122,0.1353]$} & 0.1665 & {$[0.1239,0.2101]$} \\
$\delta$ & 0.0152 & {$[0.0150,0.0155]$} & 0.0118 & {$[0.0112,0.0124]$} \\
$\tau$ & 0.6227 & {$[0.5195,0.7242]$} & 1.6634 & {$[1.4049,1.8997]$} \\
$h$ & 0.2639 & {$[0.2205,0.2985]$} & 0.3122 & {$[0.2502,0.3828]$} \\
$\kappa$ & 0.0010 & {$[0.0005,0.0014]$} & 0.0017 & {$[0.0003,0.0028]$} \\
$\varphi_{Z}$ & 0.1660 & {$[0.1114,0.2126]$} & 0.3125 & {$[0.2509,0.3651]$} \\
$\varphi^{*}$ & 0.9382 & {$[0.8958,1.0343]$} & 0.8390 & {$[0.7174,0.9683]$} \\
$\varphi_{C}$ & 0.2852 & {$[0.2657,0.2996]$} & 0.2064 & {$[0.1607,0.2463]$} \\
$\varphi_{H}$ & 0.0205 & {$[0.0086,0.0331]$} & 0.1750 & {$[0.0961,0.2511]$} \\
$\theta_{H}$ & 0.7105 & {$[0.6940,0.7250]$} & 0.8137 & {$[0.7871,0.8384]$} \\
$\theta_{L}$ & 0.8545 & {$[0.8392,0.8763]$} & 0.6626 & {$[0.5779,0.7433]$} \\
$\xi_{H}$ & 0.5881 & {$[0.5029,0.6503]$} & 0.6000 & {$[0.4947,0.7151]$} \\
$\xi_{L}$ & 0.9790 & {$[0.9625,0.9959]$} & 0.8811 & {$[0.8243,0.9346]$} \\
$\psi_{\pi}$ & 1.5720 & {$[1.5413,1.6193]$} & 2.0209 & {$[1.9161,2.1411]$} \\
$\psi_{y}$ & 0.2711 & {$[0.2323,0.3247]$} & 0.1828 & {$[0.0831,0.2845]$} \\
$\rho_{R}$ & 0.8569 & {$[0.8477,0.8704]$} & 0.8179 & {$[0.7889,0.8569]$} \\
$\gamma^{(Q)}$ & 0.4120 & {$[0.3774,0.4388]$} & 0.4085 & {$[0.2545,0.6263]$} \\
$r^{(A)}$ & 0.3368 & {$[0.3131,0.3646]$} & 0.3328 & {$[0.2717,0.3966]$} \\
$\pi^{(A)}$ & 4.8804 & {$[4.3918,5.2561]$} & 2.0724 & {$[1.5934,2.5767]$} \\
$\omega_{F}$ & 0.2889 & {$[0.2785,0.3017]$} & 0.2193 & {$[0.1877,0.2583]$} \\
$\omega_{o}$ & 0.1174 & {$[0.1022,0.1323]$} & 0.1070 & {$[0.0843,0.1348]$} \\
$\rho_{A}$ & 0.8862 & {$[0.8638,0.9167]$} & 0.7943 & {$[0.7406,0.8490]$} \\
$\rho_{o}$ & 0.9446 & {$[0.9073,0.9640]$} & 0.9557 & {$[0.9033,0.9887]$} \\
$\rho_{o^{*}}$ & 0.9563 & {$[0.9451,0.9681]$} & 0.8932 & {$[0.8282,0.9689]$} \\
$\rho_{R^{*}}$ & 0.8229 & {$[0.7971,0.8500]$} & 0.5262 & {$[0.4542,0.6228]$} \\
$\rho_{\pi^{*}}$ & 0.1795 & {$[0.1670,0.1927]$} & 0.0773 & {$[0.0237,0.1249]$} \\
$\rho_{C^{*}}$ & 0.9305 & {$[0.8788,0.9627]$} & 0.5962 & {$[0.5108,0.6791]$} \\
$\sigma_{R}$ & 0.0080 & {$[0.0067,0.0092]$} & 0.0023 & {$[0.0017,0.0029]$} \\
$\sigma_{A}$ & 0.0189 & {$[0.0157,0.0217]$} & 0.0188 & {$[0.0148,0.0228]$} \\
$\sigma_{o}$ & 0.2929 & {$[0.2509,0.3435]$} & 0.0532 & {$[0.0335,0.0723]$} \\
$\sigma_{o^{*}}$ & 0.1759 & {$[0.1470,0.2013]$} & 0.0632 & {$[0.0459,0.0798]$} \\
$\sigma_{R^{*}}$ & 0.0113 & {$[0.0093,0.0136]$} & 0.0092 & {$[0.0070,0.0112]$} \\
$\sigma_{\pi^{*}}$ & 0.0630 & {$[0.0537,0.0725]$} & 0.0307 & {$[0.0224,0.0387]$} \\
$\sigma_{C^{*}}$ & 0.0244 & {$[0.0186,0.0308]$} & 0.0186 & {$[0.0128,0.0247]$} \\
\hline & & & &
\end{tabular}

Bank of Korea's calibration, 0.58 . The weight on oil in consumption basket $\omega_{o}$ is estimated as 0.117 . Persistence parameters are estimated high except one. The posterior mean of the persistence for foreign inflation shock $\rho_{\pi^{*}}$ is 0.180 . This estimate is even lower for DSGE-VAR $(\hat{\hat{\lambda}})$.

As pointed out in Del Negro and Schorfheide (2004), information about structural parameters of the DSGE model is gathered more slowly as the DSGE prior weight loosens. When $\lambda$ is moving away from infinity priors on VAR, parameters become less tight. Therefore, we can expect that the 
Table 9.5 Variance decomposition

\begin{tabular}{lcccccc}
\hline & $\begin{array}{c}\text { Output } \\
\text { growth }\end{array}$ & $\begin{array}{c}\text { Interest } \\
\text { rate }\end{array}$ & $\begin{array}{c}\text { Core } \\
\text { inflation }\end{array}$ & $\begin{array}{c}\text { Wage } \\
\text { inflation }\end{array}$ & Ex. rate dep. & $\begin{array}{c}\text { Oil import } \\
\text { growth }\end{array}$ \\
\hline Money & 0.3444 & 0.0159 & 0.1953 & 0.1840 & 0.0757 & 0.3268 \\
Technology & 0.0580 & 0.0090 & 0.0130 & 0.0040 & 0.0012 & 0.0185 \\
Oil* & 0.1103 & 0.1674 & 0.0691 & 0.0957 & 0.0311 & 0.1226 \\
Dev. LOP & 0.2596 & 0.4039 & 0.1681 & 0.2480 & 0.0709 & 0.2910 \\
Money* & 0.0437 & 0.3343 & 0.4347 & 0.3572 & 0.2642 & 0.0502 \\
Inflation* & 0.0108 & 0.0665 & 0.1174 & 0.1094 & 0.5561 & 0.0147 \\
Consumption* & 0.1731 & 0.0030 & 0.0024 & 0.0016 & 0.0007 & 0.1762 \\
\hline
\end{tabular}

Note: "Starred" shocks on the first column denote international/foreign ones.

posterior of DSGE-VAR $(\hat{\lambda})$ is closer to the prior than the posterior distribution of the DSGE model. For many parameters it is verifiable, especially for the substitution elasticity between oil-capital aggregator and labor input of production $\phi_{H}$, and that between Home and Foreign goods consumption in core consumption bundle $\phi_{z}$.

Fluctuations of the observables originate from the structural shocks of our economy. Variance decompositions of the observables at the posterior mean are reported in table 9.5. We can easily see that the monetary policy shock has significant contributions to the variability of output growth, oil import growth, and both inflations. However, the contributions of the technology shock are negligible, less than 1 percent, especially for price variables. These findings coincide with the result from a standard New Keynesian economy. The domestic interest rate variability can be explained mostly by the oil price shock (Oil*; 17 percent), the shock on the deviation from the law of one price (LOP; 40 percent), and the international interest rate shock (Money*; 33 percent). We should note that the international oil price and the deviations from the law of one price together decide the domestic oil price, and therefore, we can say that these two shocks have large contributions in explaining the variability of the domestic interest rate, the output growth rate, and the oil import growth rate.

\subsubsection{Impulse Response Functions}

As seen previously, DSGE-VAR $(\hat{\lambda})$ attains higher marginal likelihood than the other two extremes: DSGEs and VARs. Basically, the DSGE-VAR $(\hat{\lambda})$ is a Bayesian VAR (BVAR) optimally weighted prior from the DSGE model. Hence, we can use it as the benchmark in evaluating the performance of the DSGE model. As is often the case with indirect inferences (e.g., Christiano, Eichenbaum, and Evans 2005), the performance of a DSGE model is checked by comparing impulse response functions, one from a VAR and another from the DSGE model.

Figure 9.1, panel A, depicts impulse responses with respect to a mone- 

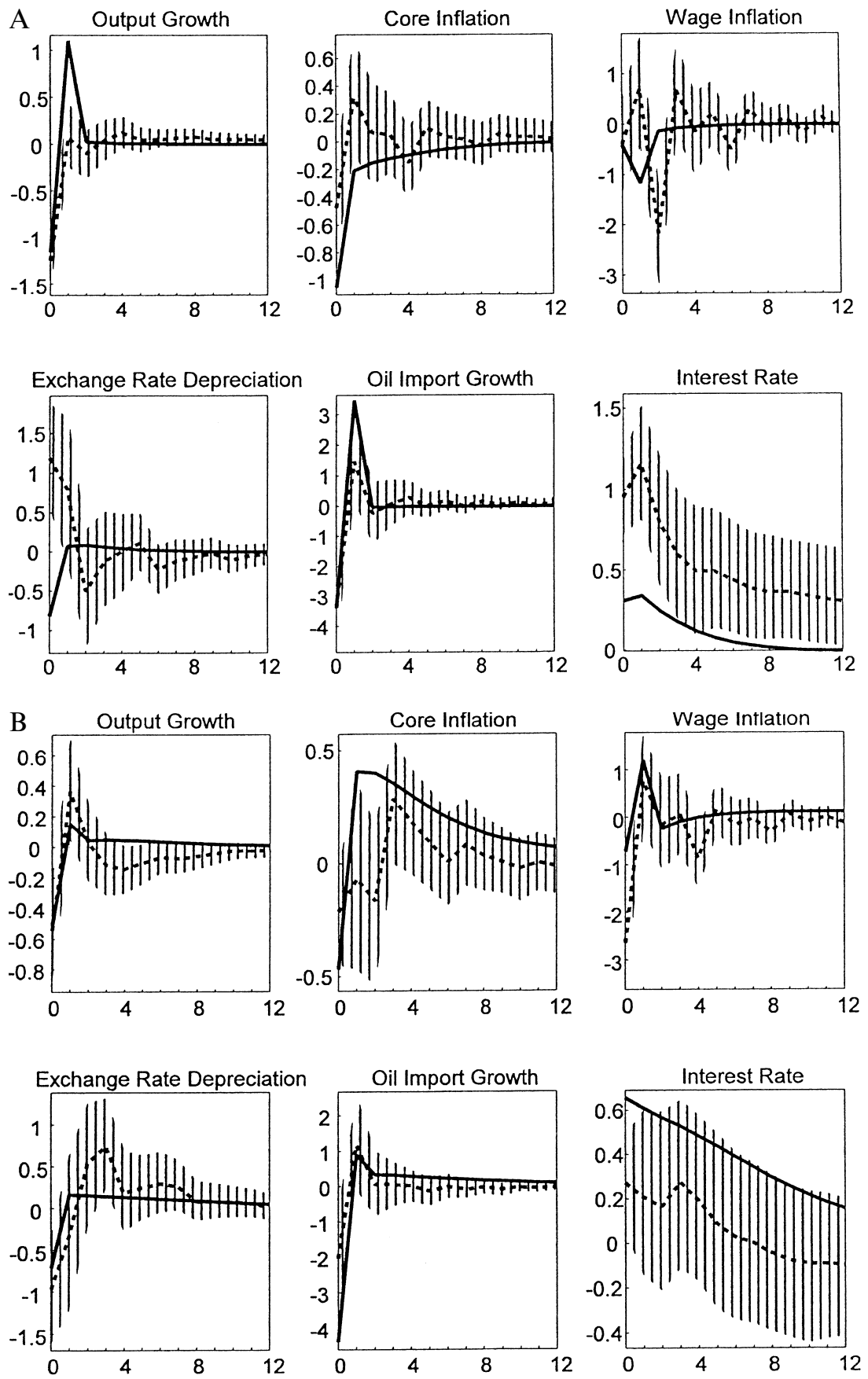

Fig. 9.1 Impulse response functions: Baseline model. $A$, monetary shock; $B$, oil price shock 
tary policy shock in the baseline economy. The posterior mean responses of the DSGE (solid line) and DSGE-VAR $(\hat{\lambda})$ (dotted line) are given, with a 90 percent coverage band (gray area) for DSGE-VAR $(\hat{\lambda})$. Responses of real international price of oil are omitted because this observable is purely exogenous and it responds only to its own shock in the model. We can see that responses from the DSGE model trace out those of DSGE-VAR $(\hat{\lambda})$. Most of responses from the baseline DSGE model show hump-shaped and prolonged effects, but these effects are quantitatively small compared to those from the DSGE-VAR $(\hat{\lambda})$. These quantitative discrepancies are originated from a relatively low value of $\hat{\lambda}$; that is, 0.5 . Some initial responses do not match, such as exchange rate depreciation.

Panel B of figure 9.1 shows responses to an oil price shock in the baseline economy. Again, response from the DSGE model mimics well those from DSGE-VAR $(\hat{\lambda})$. When a household is hit by the oil price shock it tries to reduce the oil consumption and compensate its utility loss by substituting with the core consumption bundle. Given that the estimated elasticity of substitution $\phi_{Z}$ is low (0.166), however, this desired substitution is not fully accommodated and the aggregate consumption will decrease initially. From the firm's side, the oil input can be substituted by the capital with the unit elasticity of substitution, but this channel also drives out the household consumption for higher investment. Alternatively, the reduced oil input might be compensated by an increased labor demand, but again, the substitution elasticity $\phi_{H}$ is quite low (0.021). Therefore, the initial responses of oil import growth, output growth, core inflation, and wage inflation are negative.

The responses of aforementioned variables in subsequent periods are more interesting. As time goes by, more households can adjust to the monopolistic wage in Calvo-Yun setting. Given the higher demand for the labor input, the wage inflation turns into positive. The same story goes with the core inflation, where oil consumption is replaced by the core consumption over time and more firms adjust their Home goods output prices to the monopolistic level. It looks puzzling that oil imports growth that is initially negative due to the oil price shock stays positive in subsequent periods. Even though the oil consumption decreases, the increased core consumption requires the increase in Home goods production; hence, the income effect takes place and the oil input for production eventually increases. The total response is governed by the sum of the substitution effect in direct oil consumption, and the substitution and income effects in oil input in production. If we assume the foreign consumption demands behave similarly, the income effect would be even bigger and it would keep oil import growth positive. We should note here again that these findings coincide with the impulse responses from the DSGE-VAR $(\hat{\lambda})$ - a version of Bayesian VAR with not-so-tight priors $(\hat{\lambda}=$ $0.5)$ imposed by the baseline model. 


\subsubsection{Pass-Through of Oil Price and Deviation from the Law of One Price}

The baseline model for our analysis is constructed so that the exchange rate pass-through for all but oil is perfect. However, there is a discrepancy between international oil price and domestic oil price as in (3) and deviations from the LOP are modeled as a stochastic process whose log-deviation $\hat{\zeta}_{o, t}$ follows an AR(1) process. We can see that $\hat{\zeta}_{o, t}$ takes value 0 if the passthrough is perfect, and moves away from zero otherwise. From table 9.4 it is obvious that $\xi_{o, t}$ is highly persistent across specifications, 0.9446 for DSGE and 0.9557 for DSGE-VAR $(\hat{\lambda})$. Hence, we can expect that the pass-through of oil prices into domestic price is relatively low. The pass-through rate is calculated by dividing the impulse responses of core CPI index by the responses of oil prices to oil price shock. Figure 9.2 depicts the pass-through rates of the oil price shock into the core CPI evaluated at the posterior means of the baseline model (dashed line) and DSGE-VAR $(\hat{\lambda})$ (solid line). Since the initial response of the core inflation is negative, the pass-through for the period turns out to be negative. At the two-year horizon, the pass-through reaches 0.055 for the baseline model and 0.077 for $\operatorname{DSGE}-\operatorname{VAR}(\hat{\bar{\lambda}})$, which is close to Jongwanich and Park's (2008) estimate on Korea during 1996Q1 to

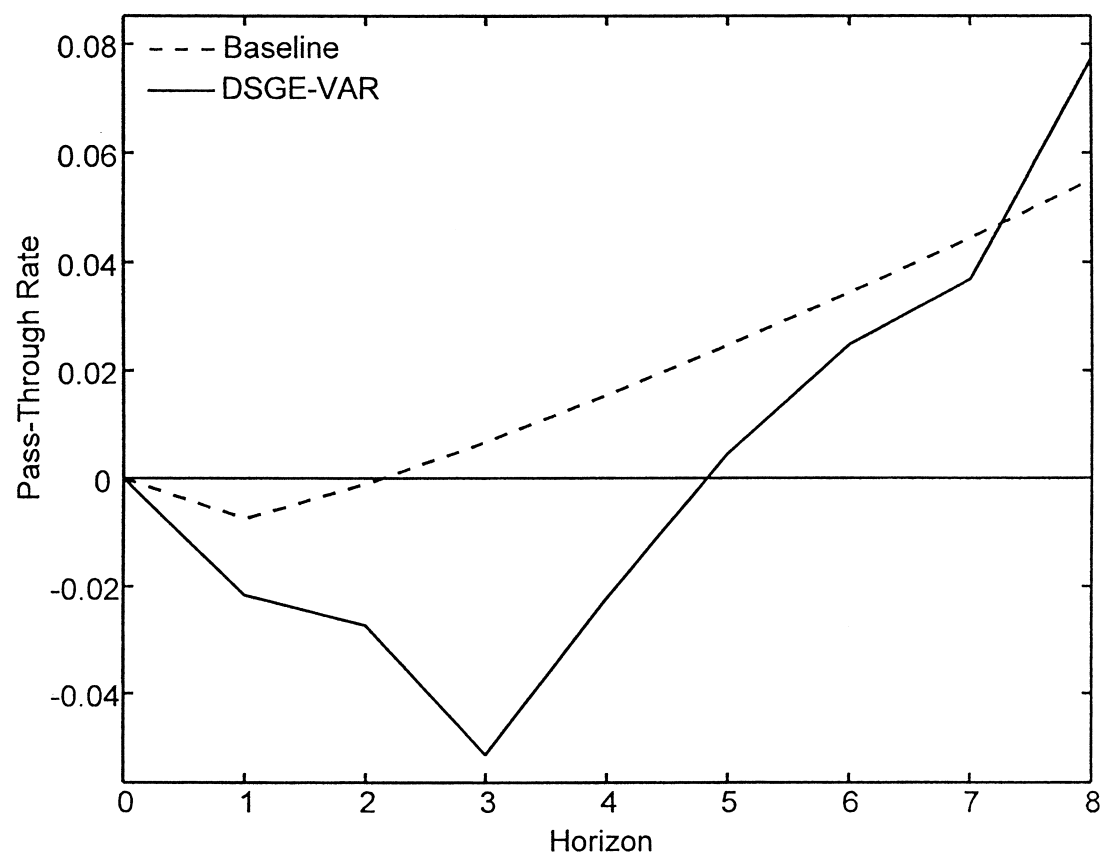

Fig. 9.2 Pass-through of international oil price 


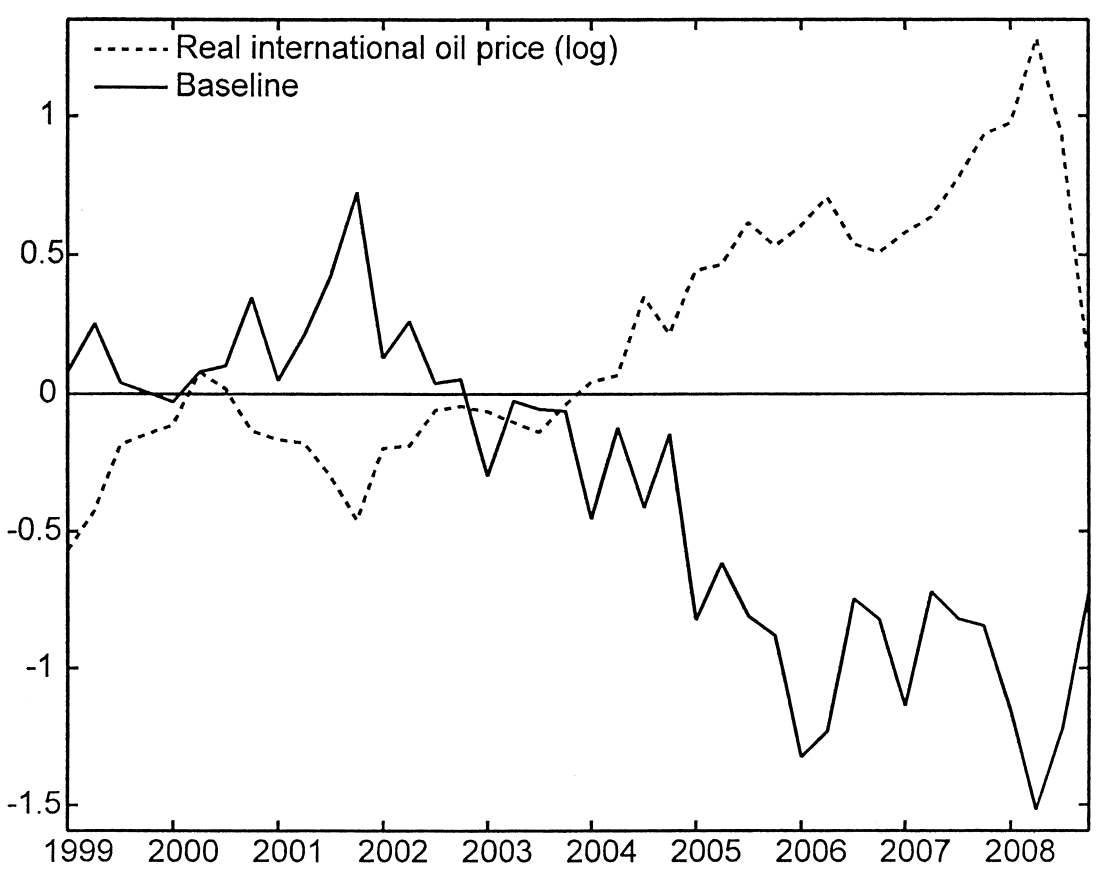

Fig. 9.3 Deviations from the Law of One Price

2008Q1 for Producer Price Index (PPI) (0.07), but much higher than theirs for CPI (0.008).

Since the deviation from the LOP $\hat{\zeta}_{o, t}$ makes one of the underlying state variables of the state space representation, we can obtain the smoothed series via Kalman filter once structural parameter values are fixed. Figure 9.3 shows these smoothed deviations from the LOP. Actual observations of log real international price of oil (dotted line) are also drawn for reference. The international oil price is stable until 2003 and takes off around 2004. We can see that the smoothed deviation from the LOP has also been moving around zero (that means the perfect pass-through of oil prices) until 2004 but decreases significantly afterwards. To explain changes in this deviation, we consider the government's reaction to an oil price shock. First we note that one of the main tax revenues of Korean government is the gasoline tax. Roughly 58 percent of the gasoline price paid by Korean customers is counted as the government revenue. Hence, the government could have lowered the gasoline tax to alleviate burdens of households and this fiscal policy could have affected the deviation from the LOP, even though the behavior of the government is not explicitly modeled in our baseline economy. Figure 9.4 depicts the gasoline price at the pump (solid line), the gasoline tax (dash-dotted line), and the tax ratio on gasoline consumption 


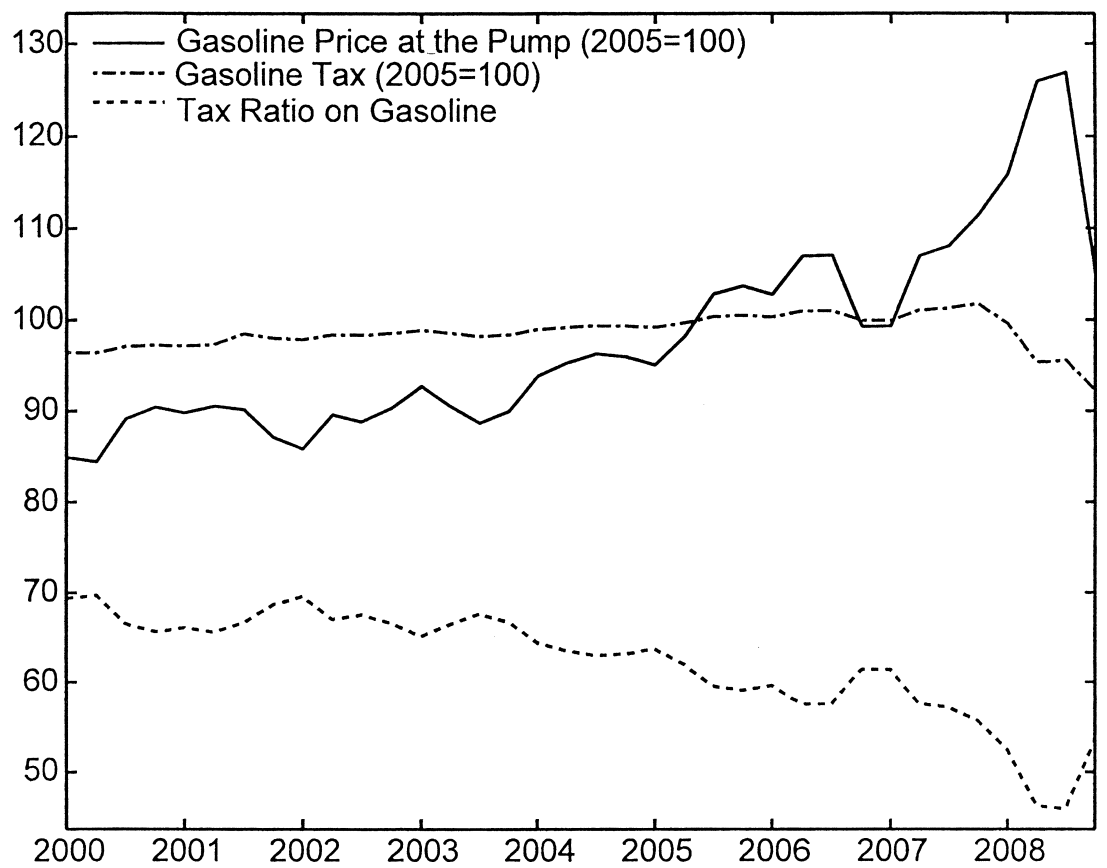

Fig. 9.4 Gasoline tax in Korea

(dotted line) during this period. In Korea, the tax on gasoline consumption consists of a per-unit tax that is time-varying and the value-added tax with fixed rate at 10 percent. As the gasoline price increases due to an oil price shock, the effective tax rate on gasoline consumption decreases because of this composition effect. Actually, the Korean government did not accommodate the oil price surge by changing the per unit tax until the end of 2007. But there was a significant tax cut on gasoline during 2008. Thus, the tax cut that accommodates the oil price shock can explain only a small fraction of the deviation from the LOP.

\subsection{Conclusion}

In this chapter we present the model economy that uses oil imports either as direct consumption or as an input of production. Within Bayesian estimation framework including DSGE-VARs, the empirical analysis is performed based on the Korean aggregate data. We find that the baseline economy produces reasonable posterior estimates of the structural parameters and works relatively well compared to impulse responses from DSGE-VAR $(\hat{\lambda})$, and that the misspecification will be very severe when either consumption or production motive of oil imports is ignored. From the variance decom- 
position analysis, we conclude that the variability of the domestic interest rate can be explained mainly by the oil price shocks transmitted to domestic oil prices. Finally, the pass-through of oil prices into the core consumption price index is relatively low and the deviation from the LOP has decreased, but the government-accommodating tax policy played a limited role during this period. Therefore, a more elaborate model on government behavior is anticipated to investigate the pass-through of oil price shocks.

\section{References}

An, S., and F. Schorfheide. 2007. Bayesian analysis of DSGE models. Econometric Reviews 26 (2-4): 113-72.

Backus, D. K., and M. J. Crucini. 2000. Oil prices and the terms of trade. Journal of International Economics 50 (1): 185-213.

Blanchard, O. J., and C. M. Kahn. 1980. The solution of linear difference models under rational expectations. Econometrica 48 (5): 1305-12.

Bouakez, H. N. Rebei, and D. Vencatachellum. 2008. Optimal pass-through of oil prices in an economy with nominal rigidities. CIRPÉE Working Paper no. $08-31$

Calvo, G. A. 1983. Staggered prices in a utility-maximizing framework. Journal of Monetary Economics 12 (3): 383-98.

Christiano, L. J., M. Eichenbaum, and C. L. Evans. 2005. Nominal rigidities and the dynamic effects of a shock to monetary policy. Journal of Political Economy 113 (1): $1-45$.

DeJong, D. N., B. F. Ingram, and C. H. Whiteman. 2000. A Bayesian approach to dynamic macroeconomics. Journal of Econometrics 98 (2): 203-23.

Del Negro, M., and F. Schorfheide. 2004. Priors from general equilibrium models for VARs. International Economic Review 45 (2): 643-73.

Del Negro, M., F. Schorfheide, F. Smets, and R. Wouters. 2007. On the fit and forecasting performance of New Keynesian models. Journal of Business and Economic Statistics 25 (2): 123-43.

Erceg, C. J., D. H. Henderson, and A. T. Levin. 2000. Optimal monetary policy with staggered wage and price contracts. Journal of Monetary Economics 46 (2): $281-313$.

Geweke, J. 1999. Computational experiments and reality. University of Iowa. Unpublished Manuscript.

Jongwanich, J., and D. Park. 2008. Inflation in developing Asia: Demand-pull or cost-push? Asian Development Bank. Working Paper.

Kang, H., and Y. Park. 2007. BOKDSGE: A DSGE model for the Korean economy. The Bank of Korea. Working Paper.

Landon-Lane, J. 1998. Bayesian comparison of dynamic macroeconomic models. $\mathrm{PhD}$ dissertation. University of Minnesota.

Medina, J. P., and C. Soto. 2005. Oil shocks and monetary policy in an estimated DSGE model for a small open economy. Working Paper no. 353, Central Bank of Chile.

Schorfheide, F. 2000. Loss function-based evaluation of DSGE models. Journal of Applied Econometrics 15 (6): 645-70. 
Sims, C. A. 2002. Solving linear rational expectations models. Computational Economics 20 (1-2): 1-20.

Smets, F., and R. Wouters. 2003. An estimated dynamic stochastic general equilibrium model of the Euro area. Journal of European Economic Association 1 (5): $1123-75$.

Taylor, J. B. 1993. Discretion versus policy rules in practice. Carnegie-Rochester Conference Series on Public Policy 39:195-214.

Uhlig, H. 1999. A toolkit for analyzing nonlinear dynamic stochastic models easily. In Computational methods for the study of dynamic economies, ed. R. Marimón and A. Scott, 30-61. Oxford: Oxford University Press.

Yun, T. 1996. Nominal price rigidity, money supply endogeneity, and business cycles. Journal of Monetary Economics 37 (2): 345-70.

\section{Comment Warwick J. McKibbin}

This interesting chapter develops a DSGE model for Korea based on the approach of Del Negro and Schorfheide (2004), but it includes oil in production and consumption. In addition to exploring the impact of oil price shocks and monetary shocks on the Korean economy, the chapter also explores whether excluding oil as an intermediate input alone or as final demand alone results in misspecification.

My comments can be divided into questions about the model specification and some comments on the empirical results that require greater elaboration.

The model specification is what becomes a conventional DSGE model, with households, firms, and government making intertemporal decisions. One feature of the model is that money is in the utility function. This is conventional in many DSGE models, but it does create a demand for money that depends on wealth rather than transactions (or income), which tends to be rejected by the data in standard econometric analysis of money demand. A transactions demand for money specification would probably fit the data better. An extension of the standard model is that consumption is allocated between one composite good and oil. In addition, firms choose production based on a CES production function of labor and a Cobb-Douglas nesting of capital and oil. The restriction of a unitary substitutability between oil and capital is a strong assumption. On U.S. data when estimated on a time series of input-output tables this assumption can be rejected (see McKibbin and Wilcoxen 1999). There is no obvious reason for this specification and in future work on the model production could easily be extended to a CES

Warwick J. McKibbin is director of the Research School of Economics and of the Centre for Applied Macroeconomic Analysis (CAMA) at the Australian National University. 